\title{
DNA Nanodevices with Selective Immune Cell Interaction and Function
}

Nishkantha Arulkumaran ${ }^{1}$, Conor Lanphere ${ }^{2}$, Charlotte Gaupp ${ }^{1}$, Jonathan R. Burns ${ }^{2 *}$, Mervyn Singer $^{1 *}$, Stefan Howorka ${ }^{2 *}$

${ }^{1}$ Division of Medicine, Bloomsbury Institute of Intensive Care Medicine, University College London, London, WC1E 6BT, United Kingdom

${ }^{2}$ Department of Chemistry, Institute of Structural Molecular Biology, University College London, London WC1H OAJ, United Kingdom 


\begin{abstract}
DNA nanotechnology produces precision nanostructures of defined chemistry. Expanding their use in biomedicine requires designed biomolecular interaction and function. Of topical interest are DNA nanostructures that function as vaccines with potential advantages over non-structured nucleic acids in terms of serum stability and selective interaction with primary human immune cells. Here we describe how compact DNA nanobarrels bind with a 400-fold selectivity via membrane anchors to white blood immune cells over erythrocytes, without affecting cell viability. The selectivity is based on the preference of the cholesterol lipid anchor for the more fluid immune cell membranes compared to the lower membrane fluidity of erythrocytes. Compacting DNA into the nanostructures also gives rise to increased serum stability. The DNA barrels furthermore functionally modulate white blood cells by suppressing the immune response to pro-inflammatory endotoxin lipopolysaccharide. This is likely due to electrostatic or steric blocking of toll-like receptors on white blood cells. Our findings on immune-cell specific DNA nanostructures may be applied for vaccine development, immunomodulatory therapy to suppress septic shock, or the targeting of bioactive substances to immune cells.
\end{abstract}

KEYWORDS DNA; DNA nanotechnology, bilayer membrane, white blood cells, lipids, immunomodulation, nanostructures

ToC GRAPHIC

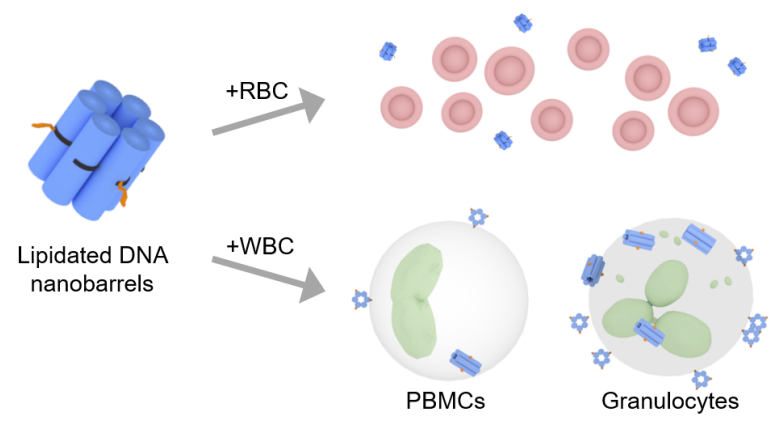


DNA nanostructures advance nanotechnology and the life sciences. Compared to other materials, DNA nanostructures have an unsurpassed highly controllable architecture which is based on predictable folding using base-pairing rules..$^{1-5}$ By exploiting these properties, the functional structures are increasingly designed to benefit areas outside DNA nanotechnology. Examples include DNA scaffolds which precisely position proteins and other biomolecular components for biophysical and molecular biological research, ${ }^{1-2,6-8}$ or as scaffold to organize enzymes into efficient multistep biocatysts. ${ }^{9}$ Furthermore, predictable changes in DNA nanostructures have been exploited for smart biosensing ${ }^{10}$ to measure $\mathrm{pH}$ inside cells ${ }^{10-12}$ or to delivery bioactive cargo into cells. ${ }^{13}$ The greatest reward is expected in biomedicine ${ }^{14-16}$ as illustrated by a DNA nanorobot to deliver anti-cancer drugs ${ }^{17}$ or larger nanostructures that mitigate acute kidney injury within animal models..$^{18-19}$

Immunology and vaccine development are of topical interests for DNA nanotechnology. Nonstructured DNA and RNA have previously been developed into vaccines against cancer. ${ }^{20-23}$ The relevance of nucleic acids-based therapy platforms has been further increased with the SARS$\mathrm{CoV}-2$ pandemic. ${ }^{24-29} \mathrm{~A}$ main advantage of mRNA type vaccines is the speed at which they can be developed and manufactured compared to traditional protein-based vaccines. Nevertheless, DNA and RNA vaccines have disadvantages including their low potency, poor uptake into immune cells, lack of stability against nucleases, and fast clearance rates..$^{20,30-31}$ These latter weaknesses have been addressed by different routes of administration and delivery ${ }^{30,32}$ using nanoparticles ${ }^{29,31}$ including Janus particles, ${ }^{33}$ or scaffold-based delivery vehicles. ${ }^{23,34-35}$ Engineering nanomaterials for higher DNA uptake and stability is also relevant for genetic engineering ${ }^{36}$ and complements insight from delivery techniques for protein therapeutics. ${ }^{37}$

To date, DNA nanotechnology has not been exploited to overcome the vaccine challenges of low stability or selective interaction. Improved stability and extended shelf-life may be obtained by compacting nucleic acids into a nanostructure. Similarly, selective functional interaction with immune cells might be achieved by site-specifically tagging of DNA nanostructures with functional tags, something which is routine. DNA nanostructures have so far been tested in vivo using mouse models to determine their stability, biodistribution, and uptake-kinetics. ${ }^{17-19,38-41}$ Yet, there are many fundamental questions on the immune-relevant cellular interaction of DNA 
structure. Is it possible for DNA nanostructure to selectively interact with immune cells in complex multicellular environments? Furthermore, how do DNA structures interact with primary cells that are directly obtained from organisms? Current studies focus mostly cultured cell lines.9-10,13,38-40,42${ }^{49}$ If selective binding is attained, do cell-tethered nanostructures affect the membrane structure, as well as cellular function and viability?

Here we report that DNA nanostructures exhibit a striking 400-fold immune-cell selective interaction with white blood cells in multi-cellular environments of primary human blood cells (Figure 1). Primary human blood cells are of interest as since intravenous injection is a standard delivery route for nucleic acids-based vaccines. In addition, determining the immune response of white blood cells to DNA nanostructures ${ }^{15}$ can lead to potential immunotherapies. Human blood is mainly composed of red blood cells (erythrocytes), and a smaller percentage of white blood cells (WBCs). The latter is a mixture of peripheral blood mononuclear cells (PBMCs) and granulocytes.

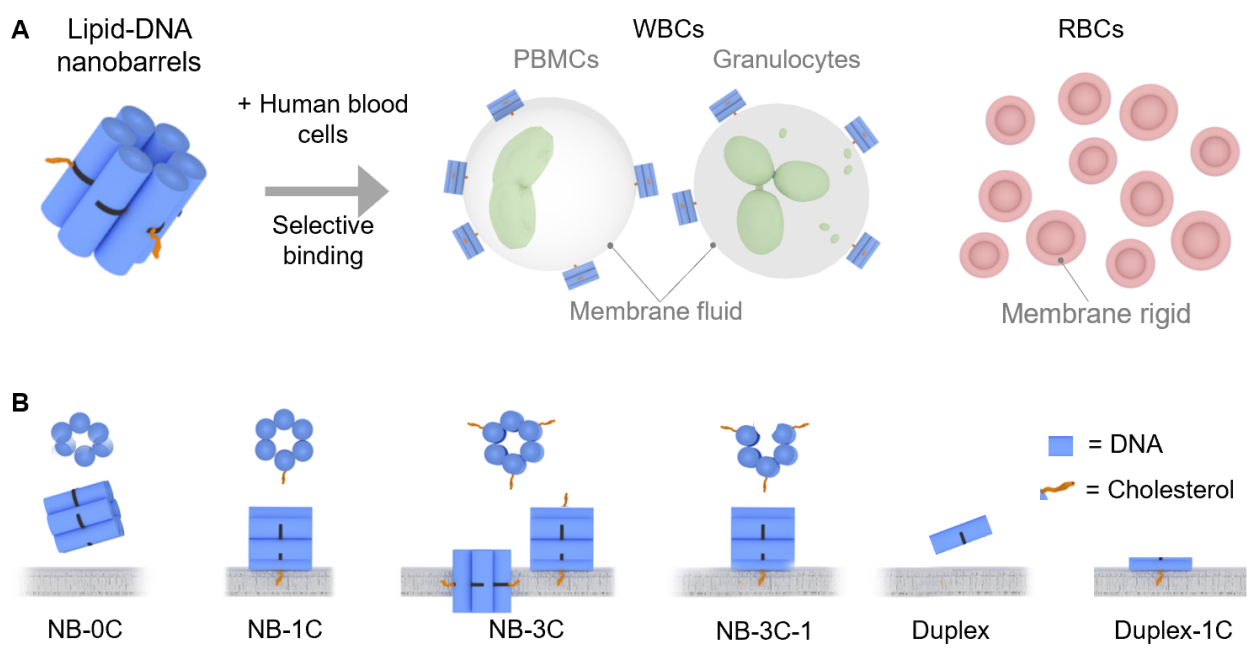

Figure 1. Cholesterol-tagged DNA nanobarrels selectively interact with white blood cells in the multi-cell environment from human blood. (A) DNA nanobarrels (blue cylinders) containing cholesterol lipid anchors (orange) selectively bind to white blood cells (WBCs) composed of peripheral blood mononuclear cells (PBMCs) and granulocytes, rather than red blood cells (RBCs). (B) Top and side view of DNA nanostructures used in this study and their proposed membrane interaction, from left to right: Control barrels NB-1C and NB-0C which are expected 
to tether and not bind to lipid bilayers, respectively, while active barrel NB-3C can span membranes. Additional control structure NB-3C-1 is expected to tether to lipid bilayers, similar to a duplex with a single cholesterol anchor.

To achieve targeted interaction with white blood cells, we developed a strategy which harnesses the differences in membrane composition between white blood cells and non-target red blood cells. ${ }^{50}$ White blood cells have a lower content of cholesterol and hence higher membrane fluidity. ${ }^{51-52}$ We surmised that DNA structures with a bilayer inserting cholesterol-tag would preferentially bind to the more fluid white blood cell membranes. We tested our hypothesis with a compact sub-10 nm-sized nanobarrel composed of a bundle of six interlinked duplexes (Figure 1). ${ }^{53}$ The DNA nanobarrel carries up to three cholesterol lipid anchors (NB-3C, Figure 1A, 1B). These have been shown to mediate binding to synthetic bilayer membranes ${ }^{54-57}$ but their ability to select for cell types is unknown. Our study shows that the 400 -fold selective binding of cholesterolDNA nanobarrels to white blood cells over erythrocytes does not cause any detectable puncturing or disruption to the cell membrane, thereby leaving cell viability unaffected. Selective barrels, unexpectedly, functionally modulate the immune cells by suppressing the immune response towards an endotoxin (lipopolysaccharide) while being stable in all tested biological media. Our report advances the fundamental understanding of DNA nanostructures in complex multicellular environments and may contribute to future biomedical developments.

\section{RESULTS/DISCUSSION}

DNA nanobarrels with up to three cholesterol anchors. To test that DNA devices can selectively interact with blood cell membranes, we used DNA nanobarrels composed of six DNA duplexes which are interlinked to form a six-helical bundle measuring 9 x 5 x $5 \mathrm{~nm}$ (Figure 1B, SI Figure S1, Tables S1, S2). ${ }^{53}$ Each hollow barrel has an inner lumen with a diameter of $2 \mathrm{~nm}$. Three DNA nanobarrel constructs were examined. NB-3C, NB-1C, and NB-0C which contain 3, 1 and 0 cholesterol lipid anchors, respectively. The cholesterol anchors are positioned in variant NB-3C symmetrically around the 6 helical barrel to aid membrane spanning behavior. Cholesterol anchors were chosen to mediate the selective binding to white blood cells. NB-3C has been previously shown to insert into and porate the membrane to enable ion transport ${ }^{53-55}$ while remaining largely monodispersed in the membrane spanning and membrane-bound form. ${ }^{55}$ DNA barrel NB-1C 
serves as negative controls as its single cholesterol anchor should only lead to membrane tethering but not spanning, while barrel NB-0C without cholesterol should not bind to any cellular bilayers (Figure 1B). Additionally, a structurally incomplete NB-3C-1 construct containing 3 lipid anchors but lacking one unmodified strand was assayed to probe the influence of the barrel structure. Finally, single and double stranded oligonucleotides were used to determine the effect of linear DNA against assembled DNA barrels (Tables S1, S2).

DNA nanobarrel assembly and characterization. The DNA nanobarrels were self-assembled by mixing equimolar ratios of each component oligonucleotide, followed by thermal annealing (Tables S1, S2). Successful nanobarrel assembly in biocompatible PBS buffer was confirmed using polyacrylamide gel electrophoresis (Figure S2). The assembled structures migrated with well-defined bands suggesting homogeneously folded products. Increasing the cholesterol number within the nanobarrel resulted in upshifted gel-band mobilities (Figure S2).

DNA nanobarrels are stable in biological media. The structural stability of the DNA nanobarrels in biological media was examined with a temperature-induced unfolding assay. The melting temperature $\left(\mathrm{T}_{\mathrm{m}}\right)$ of the DNA nanostructures was determined by monitoring fluorescence resonance energy transfer (FRET) upon heating which is a tested tool to map the local structure of DNA nanostructures in detail. ${ }^{54,58}$ The FRET reporter dyes (fluorescein donor and TAMRA acceptor) were successfully incorporated into the DNA nanostructures (Figure S3). ${ }^{59}$ At temperatures below the $T_{m}$, the nanobarrels are assembled, and the attached FRET pairs are held in close contact, resulting in a high FRET efficiency with corresponding low donor fluorescence (Figure S3). At temperatures above the melting transition, the nanobarrels' strands dissociate leading to increased donor-acceptor distances, and higher donor emission (Figure S3).

The $\mathrm{T}_{\mathrm{m}}$ values for nanobarrels NB-0C and NB-3C in a range of biological media is shown in Table 1. The buffer systems assayed included PBS (nanobarrel folding buffer), Hank's buffered saline (HBSS), heat-inactivated human serum (HIS), human serum (HS) and whole blood (WB). In all media, the $T_{m}$ values were higher or equal to PBS (Table 1, time point $0 \mathrm{~h}$ ), suggesting that the DNA nanobarrels remain stable under these diverse conditions. 
Table 1. FRET-derived melting temperatures $\left(T_{m}\right)$ of DNA nanobarrels in biological media ${ }^{a}$.

\begin{tabular}{cccccc}
\hline Construct & PBS & HBSS & HIS & HS & WB \\
\hline NB-0C 0 & $46.2 .7 \pm 0.6$ & $48.0 \pm 2.0$ & $47.2 \pm 1.2$ & $46.8 \pm 1.1$ & $46.2 \pm 0.3$ \\
NB-0C 24 h & $49.2 .3 \pm 0.3$ & $48.8 \pm 0.3$ & $48.3 \pm 0.3$ & $48.3 \pm 0.3$ & $47.3 \pm 0.3$ \\
NB-3C 0 & $47.0 \pm 0.0$ & $47.0 \pm 0.0$ & $47.7 \pm 0.3$ & $47.7 \pm 0.3$ & $47.8 \pm 0.3$ \\
NB-3C 24 h & $48.3 \pm 0.8$ & $49.7 \pm 0.3$ & $48.5 \pm 0.5$ & $50.2 \pm 0.3$ & $48.7 \pm 0.6$ \\
\hline
\end{tabular}

${ }^{a}$ NB-0C or NB-C at $0.1 \mu \mathrm{M}$ were incubated for either 0 or $24 \mathrm{~h}$ in phosphate buffered saline (PBS), Hank's buffered saline (HBSS), heat-inactivated human serum (HIS), human serum (HS) of whole blood (WB) followed by determining the $\mathrm{T}_{\mathrm{m}}$ via melting profile analysis. Values are averages from 3 independent repeats,

The melting analysis also helped probe if the nanobarrels are resilient against DNA nucleases found in whole blood and human serum. The $\mathrm{T}_{\mathrm{m}}$ values showed no change (Table 1, time point 24 h) implying the DNA barrels withstand DNase activity found in these two bodily fluids for at least $24 \mathrm{~h}$. Resilience against nucleases was also found using gel electrophoresis readout (Figure S4). DNA barrels were, however, prone to digestion when DNAse I was added to samples, both in electrophoresis (Figure S4) and UV melting profiles analysis (Figure S3). Interestingly, the DNA nanobarrels were of higher stability when compared to a reference tetrahedral DNA nanostructure with less densely packed duplexes (Figures S3, S5). ${ }^{60}$

Nanobarrels were furthermore examined for possible aggregation using confocal laser scanning microscopy (CLSM). Previous studies have indicated that cholesterol-tagged DNA barrels are soluble in protein-free buffers but aggregate in the presence of serum proteins ${ }^{59}$ Using a dyelabelled NB-3C barrel, no aggregation was observed in PBS or HBSS, but micron-sized aggregates occurred in human serum (Figure S6). The large aggregates were due to the cholesterol anchors since NB-0C did not form any visible aggregates in either HBSS or human serum (data not shown). The subsequent experiments were conducted in HBSS to prevent aggregation.

DNA nanobarrels bind selectively to white blood cells via cholesterol anchors. The interaction of nanobarrels with human blood cells was investigated to test whether the cholesterol lipid anchors can mediate selective interaction with white blood cells. Fluorescently labeled versions of DNA barrels NB-0C, NB-1C, and NB-3C (500 nM) were incubated with blood cells in HBSS. CLSM revealed fluorescent halos around white blood cells incubated with NB-3C (Figure 2A) 
implying that the barrel tethers to the cell membrane. Cholesterol was required for cell membrane binding since NB-0C did not form halos (Figure 2A). Microscopy further confirmed that nanobarrels did not bind to red blood cells. The data demonstrate that NB-3C bound to white blood cells with over very large 400-fold selectivity compared to erythrocytes (Figure 2A), thereby validating our proposed model on membrane fluidity-controlled interaction with cell membranes.
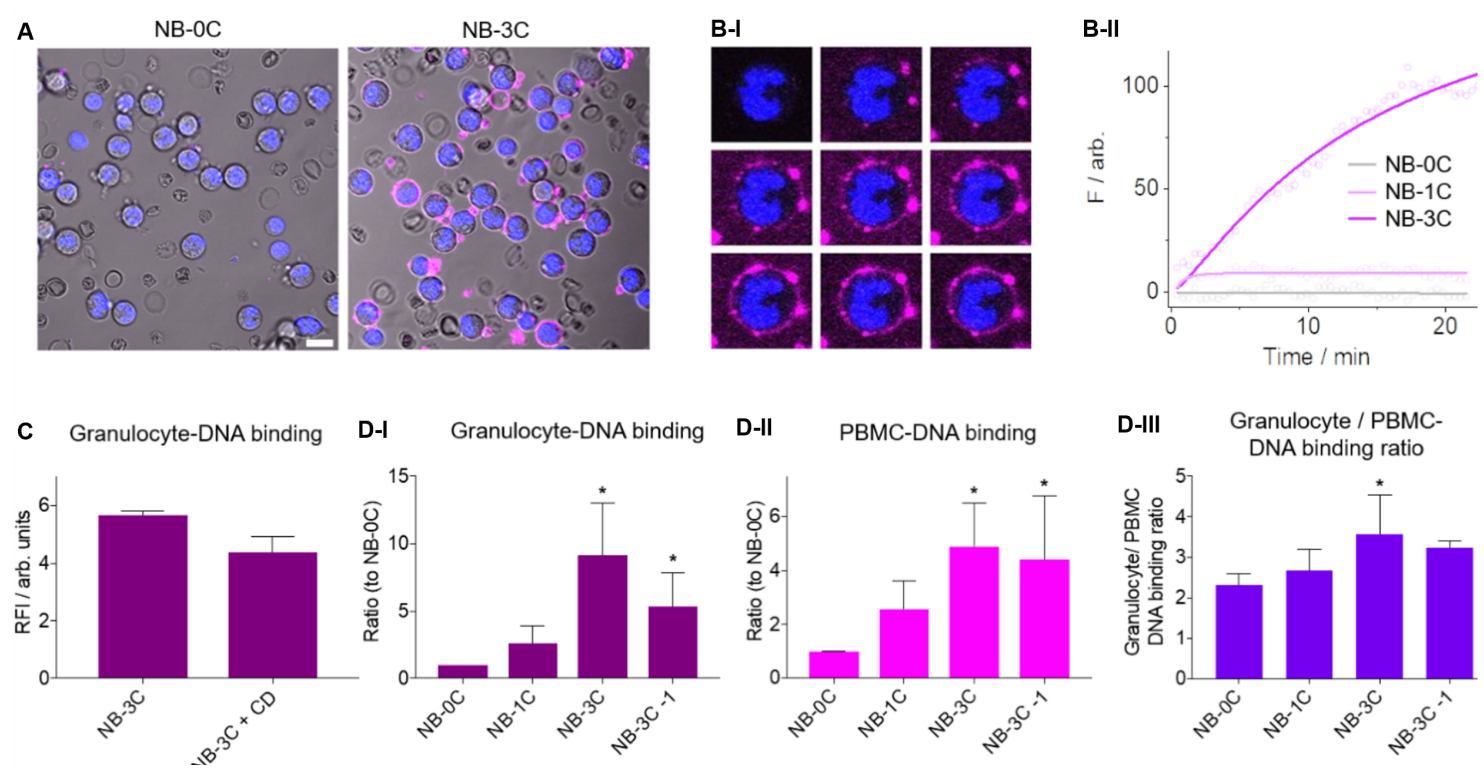

Figure 2. DNA nanobarrels' highly selective binding to immune cells. (A) CLSM analysis of DNA nanobarrels (magenta channel) $(500 \mathrm{nM})$ with white blood cells (WBC) (blue channel) in Hank's buffered saline (HBSS), scale bar $10 \mu \mathrm{m}$. (B-I) CLSM time series of WBCs upon addition of NB3C (500 nM) in HBSS, NB-3C was added between the first and second frames, where each frame represents a 5-min interval and displays an area of $12 \mu \mathrm{m} \times 12 \mu \mathrm{m}$. (B-II) CLSM-derived membrane binding kinetics of NB-0C (grey), NB-1C (pink) and NB-3C (purple) to WBCs. (C) Pre-treatment of WBCs with cytochalasin-D (CD), an inhibitor of actin cytoskeleton and phagocytosis, does not significantly reduce DNA nanobarrels association with polymorphonuclear cells. (D) Flow cytometric analysis comparing different barrel constructs' binding (250 nM) and localization towards (D-I) granulocytes and (D-II) PBMCs. (D-III) In HBSS, significantly greater binding to granulocytes compared to PBMCs is observed for NB-3C and NB-3C-1 constructs compared to NB-0C. Data represents median and interquartile range, and experiments conducted 
with $\geq 6$ biological replicates; apart from $C$, which was done with 3 technical replicates $(* p<$ $0.05)$.

The strikingly high selective binding to WBCs occurred within a few minutes of nanobarrel addition (Figure 2B-I). Three cholesterols were required for effective WBC binding as shown by the poor binding of NB-1C (Figure 2B-II). In further analysis, cell-bound NB-3C remained on the surface of WBCs with minor cell-uptake. The few internalized barrels co-localized with lysosomes (Figure S7). The negligible internalization was confirmed by blocking phagocytosis with actininhibitor cytochalasin-D (CD) and flow cytometry (Figure 2C). The observed minimal change in bound NB-3C ( $\mathrm{p}=0.10)$ implies that the barrels remain on the membranes of native white blood cells.

Flow cytometry was used to further distinguish whether barrels bind preferentially to any of the specific white blood cell classes of granulocytes and peripheral blood mononuclear cells (PBMCs). Cells were incubated with healthy volunteer immune cells for 90 min with the A647-tagged DNA nanobarrel constructs $(250 \mathrm{nM})$ and subjected to fluorescence activated cell sorting (FACS) (Figure 2D-I, 2D-II; Figure S8). The analysis revealed that nanobarrels bind weakly preferentially to granulocytes over PBMCs (Figure 2D-III). For NB-3C, the binding was 3.6-fold stronger for granulocytes $(\mathrm{p}=0.004)$ (Figure 2D-III). Furthermore, within each cell subset, binding increased with the barrels' cholesterol number (Figure 2D-II, 2D-III). For example, NB-3C bound 9.2-fold more than NB-0C to granulocytes ( $\mathrm{p}<0.001)$ and 4.9-fold more to PBMCs $(\mathrm{p}<0.001)$ (Figure 2DII and 2D-III, respectively). The selective interaction with granulocytes could be due to difference in the membrane proteins on the PDMC but is nonetheless small when compared to the 400selectivity between white blood cells and erythrocytes.

NB-3C binding to WBCs was also compatible with human serum. In CLSM analysis, the fluorescent halo around WBCs was maintained when the cells were first incubated with NB-3C in HBSS for $5 \mathrm{~min}$, and then transferred into human serum (Figure S6) indicating that serum proteins did not interfere with the interaction between the barrels and the WBCs. 
Our data on DNA barrels binding to WBC suggest a direct cholesterol-mediated binding to the membrane rather than indirect anchoring via neutrophil extracellular traps (NETs) which are networks of extracellular fibers, primarily composed of DNA from neutrophil. ${ }^{61}$ Extracellular NETs are unlikely to be the reason of DNA nanostructure capture for three reasons: (i) Our confocal data indicate clear membrane binding and intense fluorescent halos of fluorophore-tagged DNA nanobarrels surrounding the cells. (ii) Our flow cytometry analysis demonstrates cellassociated DNA nanobarrels while NET-captured particles would be extracellular and therefore not detected on cells with FACS. Finally, (iii) NET staining dye DAPI does not lead to an extracellular DNA signal in our results.

DNA nanobarrels do not puncture white blood cell membranes. We evaluated whether barrel binding leads to membrane puncturing of granulocytes' and PBMCs' membranes. Cholesteroltagged barrels have previously been shown to porate synthetic bilayers to enable ion transport. ${ }^{53-55}$ Any puncturing of cellular membranes would drastically lower the usefulness of DNA barrels an immunological agent. We probed any possible puncturing of cell membranes by monitoring passive transport of the water-soluble fluorescent dye Atto647. The expected dye flux ${ }^{54}$ across into synthetic membranes was established with unilamellar vesicles (GUVs)(Figure 3A). NB-3C bound to GUVs and transported dye, as demonstrated by CLSM (Figure 3B) and FACS (Figure 3C), respectively. The membrane activity of $\mathrm{NB}-3 \mathrm{C}$ was due to the cholesterol anchors as the negative control NB-0C did not induce flow (Figure 3C).

In contrast to barrel-induced poration of synthetic bilayers, granulocytes and PBMCs did not display dye transport even after $6 \mathrm{~h}$ of incubation with NB-3C (Figure 3D, 3E-I, 3E-II). This finding suggests that the DNA barrel tethers side-on to the cell membrane (Figure 3D) rather than spanning it (Figure 3A). The desirable lack of barrel insertion into granulocytes and PBMC membranes may be due to steric hinderance by the densely packed proteins on the cell surface. 

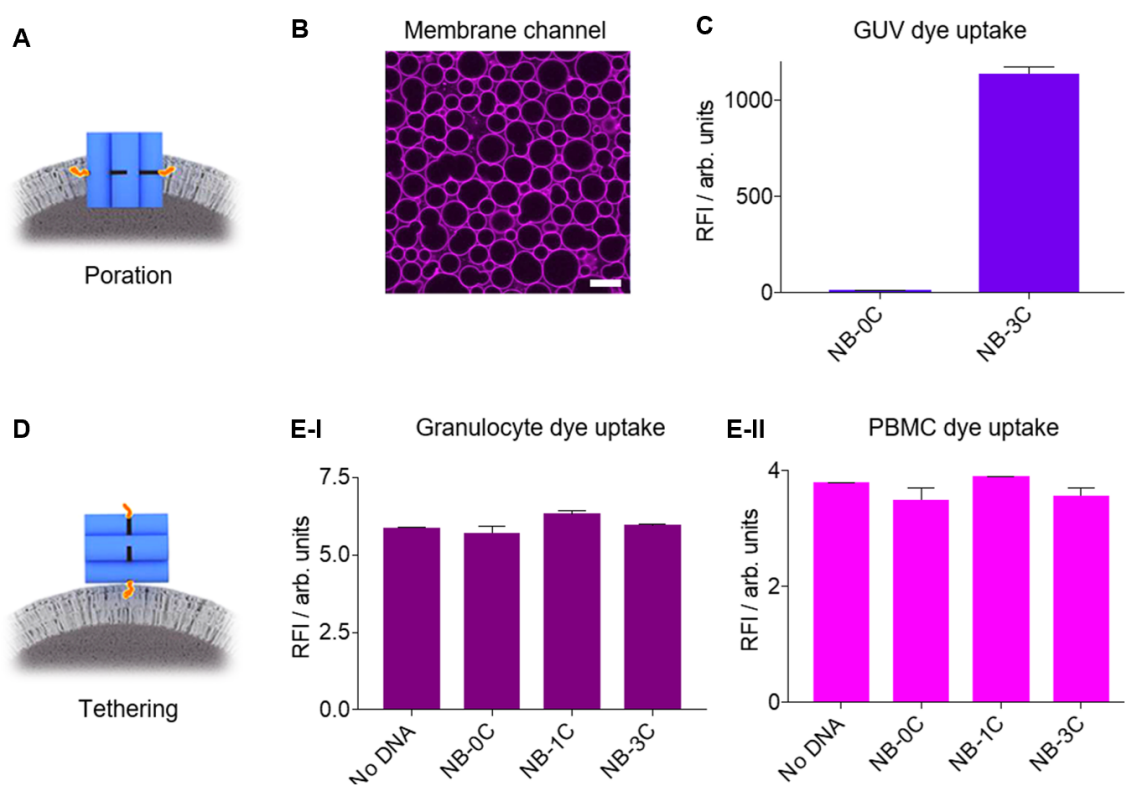

Figure 3. DNA nanobarrels do not porate white blood cell membranes. (A) Schematic representation of bilayer-spanning alignment of NB-3C. (B) CLSM showing strong NB-3C (magenta channel) binding to GUVs. Sale bar, $10 \mu \mathrm{m}$. (C) Flow cytometry analysis on the NB-3C mediated influx of Atto647 into GUVs. (D) Schematic representation of NB-3C in a membranetethered orientation. (E) FACs analysis of (E-I) granulocytes and (E-I) PBMCs reveals no significant nanobarrel-mediated Atto647 uptake into cells. Data represents median and interquartile range, and experiments conducted with 3 replicates; apart from (E), which was done with 6 biological replicates $(* \mathrm{p}<0.05)$.

DNA nanobarrels do not affect the viability of white and red blood cells. Having established selective and non-rupturing nanobarrel binding to white blood cells, we tested any effect on cell viability. As expected from their non-puncturing membrane binding, WBCs viability was unaffected after $6 \mathrm{~h}$ of nanobarrel incubation (Figure 4A, 4B). Assessing viability for longer is not possible as the primary granulocyte cell type of neutrophiles become activated after a few $\mathrm{h}$ when incubated ex-vivo. ${ }^{62}$ The barrels were also non-toxic to RBCs. Neither NB-3C and NB-0C bound to erythrocytes in CLSM analysis (Figure 4C-I), and the cells' viability was not compromised after $4 \mathrm{~h}$ nanobarrel incubation, using a haemolysis read-out (Figure 4C-II). 


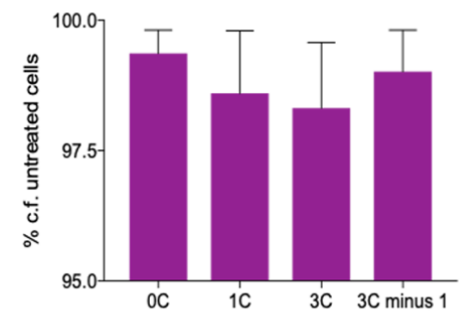

C-I

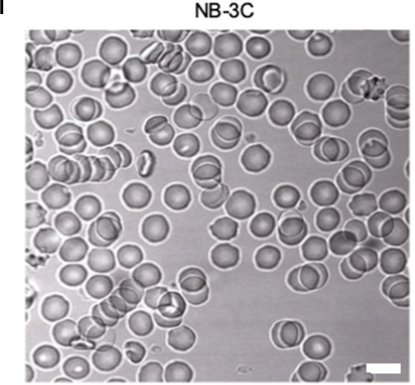

B

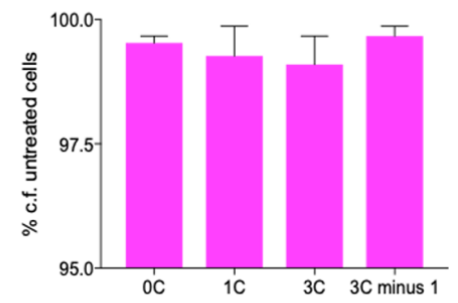

C-II

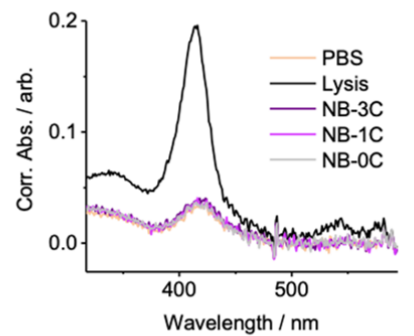

Figure 4. DNA nanobarrels do not affect the viability of white and red blood cells. (A, B) Viability assays in serum-free conditions after $6 \mathrm{~h}$ incubation for (A) granulocytes and (B) PBMCs demonstrate no significant loss in cell viability compared to untreated controls. (C-I) CLSM images of NB-3C with RBCs in HBSS. Scale bar, $10 \mu \mathrm{m}$. (C-II) UV-vis absorbance spectra of RBCs with either NB-3C (purple), NB-1C (pink) and NB-0C (grey), and controls PBS (orange) and lysed RBCs (black) in HBSS. Data represents median and interquartile range, and experiments conducted with 6 biological replicates $(* \mathrm{p}<0.05)$.

DNA nanobarrels initiate a differential immune response in white blood cells. Having established the barrels' non-toxic and highly selective binding to white blood cells, we next investigated whether DNA barrels trigger a change in immune function. DNA binding to other, cultured immune cells is known to lead to a proinflammatory reaction. ${ }^{63-64}$ We probed whether the DNA barrels also behave in a similar way. To assess the white blood cells' immune response to DNA barrels, we monitored first the production of intracellular reactive oxygen species (ROS) using the free radical-sensitive fluorophore dihydroethidium. ${ }^{65}$ When WBCs were challenged with nanobarrels, no increase in ROS levels was detected in granulocytes $(\mathrm{p}=0.41)$ (Figure 5A-I) or PBMCs ( $\mathrm{p}=0.06$ ) (Figure 5A-II) after $90 \mathrm{~min}$ of incubation in HBSS. Similar low levels of ROS were obtained when WBCs were challenged with DNA barrels in whole blood. Only a small 1.6- 
fold increase in ROS level was observed in granulocytes incubated with NB-0C ( $p=0.032$ ) (Figure S10). The absence of an intense ROS immune response is unexpected considering the strong binding of DNA barrels, and a typically strong immune response to DNA starnds. ${ }^{45,66}$ The molecular reason for our observed lower response could lie in the highly compact nature of the DNA nanobarrel which is different to the looser conformation of the previously tested nanostructures with single or double stranded DNA appendages. ${ }^{45,49,66-67}$ Compacted DNA might not be a good substrate for the ROS-generating pathway. ${ }^{68}$
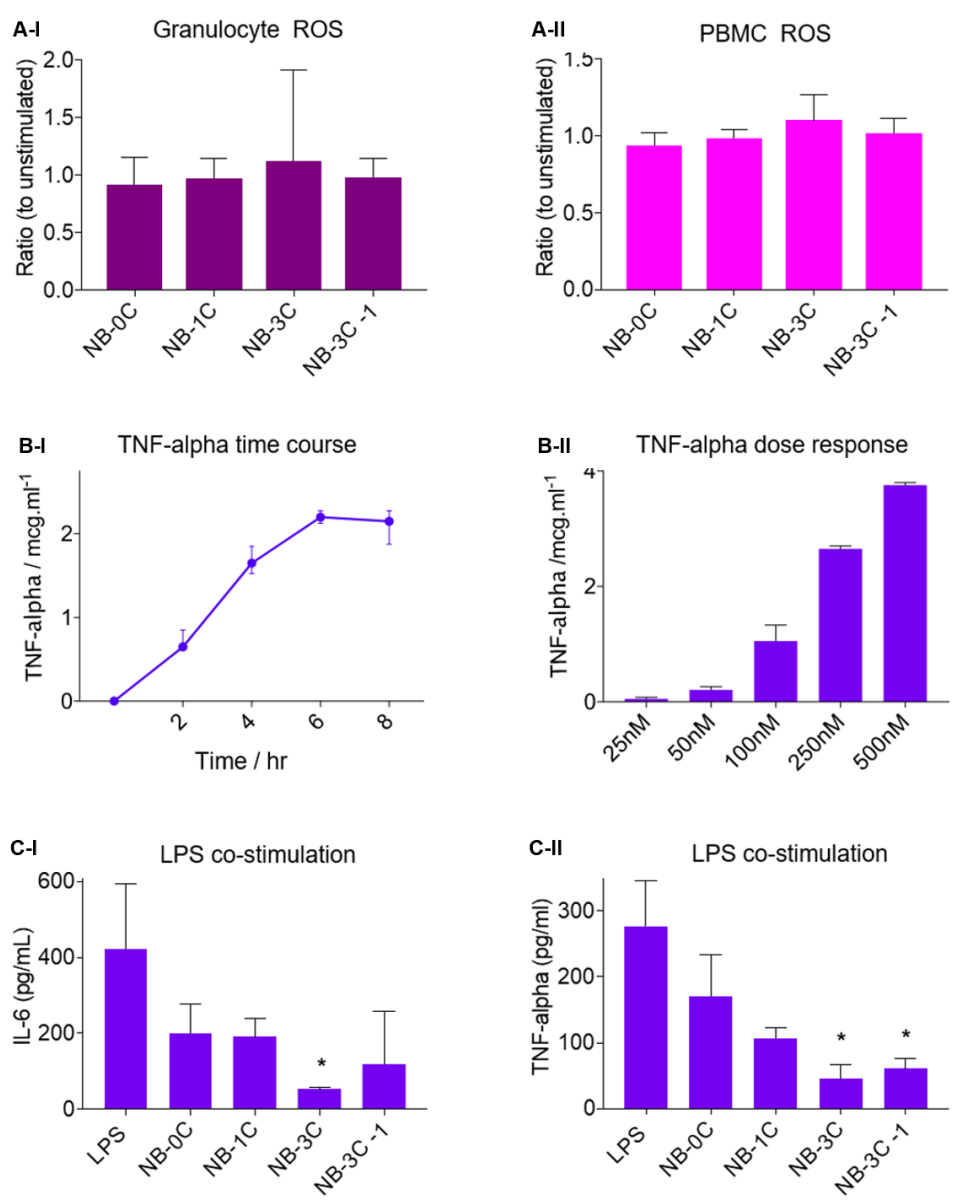

Figure 5. The immune response of DNA nanobarrels ex-vivo. (A) Flow cytometry analysis showing ROS production in serum-free conditions for (A-I) granulocytes $(\mathrm{p}=0.41)$ and (A-II) PBMCs ( $\mathrm{p}=0.056)$ following $90 \mathrm{~min}$ incubation. (B-I) In whole blood, release of cytokines occurs after $90 \mathrm{~min}$ and peaks at $6 \mathrm{~h}$ with NB-3C incubation; (B-II) a dose-dependent increase in proinflammatory cytokine TNF-alpha is seen following $6 \mathrm{~h}$ of incubation with NB-3C in whole blood. 
(C) Incubation of immune cells with DNA nanobarrels for $90 \mathrm{~min}$ followed by addition of LPS for $5 \mathrm{~h}$ results in a cholesterol-dependent reduction in LPS-induced pro-inflammatory cytokine release of (C-I) IL-6 and (C-II) TNF-alpha. Data represents median and interquartile range, and experiments were conducted with $\geq 3$ biological replicates; each with 3 technical replicates $(* \mathrm{p}<$ $0.05)$.

To further gain insight into the immune response, we monitored the release of pro-inflammatory cytokines interleukin-6 (IL-6) and tumor necrosis factor-alpha (TNF-alpha). Cytokines IL-6 or TNF-alpha levels were not elevated following $6 \mathrm{~h}$ incubation in HBSS (data not shown). Cytokine production was, however, significantly elevated in the presence of serum co-factors. For example, TNF-alpha levels were higher upon incubation in whole blood ( $\mathrm{p}=0.002)$ (Figure 5BI, B-II). Under these conditions, the TNF-alpha level was proportional to the incubation duration up to $6 \mathrm{~h}$ (Figure 5B-I) and the nanobarrel NB-3C concentration (Figure 5B-II). The data on elevated cytokine production yet low ROS levels indicate that DNA barrels lead to a differential immune response.

\section{Lipidated DNA nanobarrels lower the immune response after stimulation with inflammatory} tumor promotors and endotoxins. After establishing the base-line response to the DNA nanostructures, we explored the more complex topic of how the barrels alter the immune reaction to strong inflammatory stimuli. In particular, we examined how pre-incubation with barrels affects the granulocytes' reaction to an inflammatory stimulant and tumor promotor phorbol 12-myristate 13-acetate (PMA). Usually, PMA intracellularly activates the protein kinase $\mathrm{C}$ pathway resulting in a respiratory burst with increased production of ROS superoxides. ${ }^{69}$ Pre-incubation with DNA barrels for 90 min led, however, to a $40 \%$ lower production of ROS compared to non-pre-treatment $(\mathrm{p}=0.052)$ (Figure S9). This surprising reduction was found for all types of DNA barrels implying a limited influence of the cholesterol anchors. The cholesterol-independent effect of DNA barrels may be rationalized by the molecular interaction of PMA which acts independently of cell surface receptors and should hence not directly compete with DNA barrel binding on the cell membrane.

We also tested how pre-incubation alters the reaction to endotoxin lipopolysaccharide (LPS) which binds on the cell membrane's toll-like receptors. Addition of the endotoxin usually results in a significant increase in cytokine release, as found when granulocytes were challenged with LPS 
(100 ng/mL) for $4 \mathrm{~h}$ (Figure 5C-I, Figure S7). However, the response was suppressed when immune cells were first incubated with DNA nanobarrels for $90 \mathrm{~min}$ followed by LPS. For example, pre-incubation by NB-3C significantly reduced the release of cytokine IL-6 9.4-fold $(\mathrm{p}=0.01)$ and TNF-alpha levels 6.4-fold ( $\mathrm{p}=0.007)$ (Figure 5C-I, Figure S9); LPS did not alter ROS (data not shown). The suppression of the cytokine response was dependent on the number of cholesterols, with NB-3C displaying the biggest change $(\mathrm{p}=0.02)$ (Figure 5C-II). The cholesteroldependence may be explained by the competitive binding to toll-like receptors of the DNA barrels and the equally negatively charged LPS. Our endotoxin data underscore that DNA barrels lead to a surprising immune suppression for two classes of inflammatory stimuli.

The immune inhibitory effect is mostly due to the DNA component of the DNA nanobarrels rather than the cholesterol anchors. This was demonstrated by incubating immune cells with watersoluble cholesterol-tagged poly(ethylene glycol)(PEG) for $90 \mathrm{~min}$ followed by addition of LPS. If the DNA nanostructure would be the dominant factor, then cholesterol-PEG would not lead to a strong reduction of LPS-induced TNF-alpha release. Indeed, cholesterol-PEG resulted in a very modest drop (Figure S10). The small but detectable influence could be related to the LPSscavenging property of similar hydrophobically-tagged polymers..$^{70}$

\section{CONCLUSIONS}

DNA nanotechnology can produce highly defined materials for biomedical applications. Our reveals how DNA nanostructures behave in multi-cellular environments with impact in cellular targeting, cell membrane biology, and immunology including vaccine development. Our findings are based on biologically important and biotechnologically representative components: blood cells and an antibody-sized DNA nanostructure equipped with lipid cholesterol tags.

Our study delivers three fundamental insights. Firstly, we establish a 400-fold preferential binding of the DNA nanobarrel structures to white blood cells compared to red blood cells (Figure 6). The rapid, cellular binding only occurs with cholesterol labeled DNA structures. Previous studies on synthetic membrane bilayers did not investigate selective binding. ${ }^{54-55}$ The cellular targeting is attributed to the difference in lipid membrane composition of the two cell classes whereby WBCs 
membranes have a lower content of cholesterol than RBCs.$^{50}$ In particular, the white blood cells' lower content of cholesterol leads to higher membrane nanofluidity ${ }^{51-52}$ due to dynamic voids within the bilayer.$^{71}$ Fluid membranes with voids can, following our explanation of selectivity, be filled with cholesterol-tags of DNA barrels. The picture is likely more complicated as other lipid components in the two cells may also influence the interaction with the DNA nanostructures.

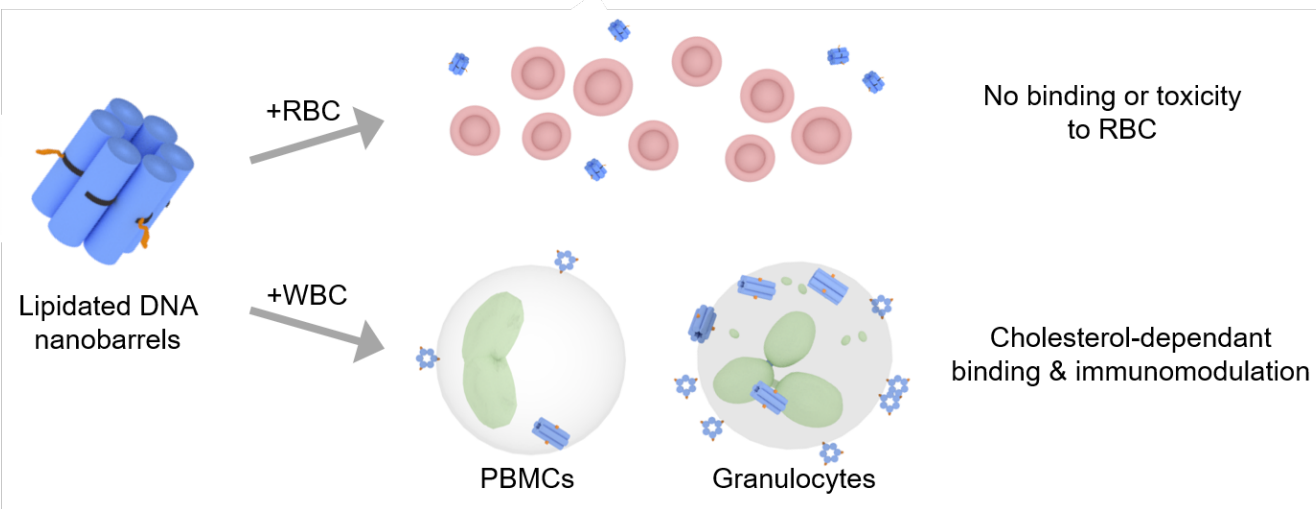

Figure 6. Overview of results, DNA nanobarrels (blue cylinders) containing cholesterol lipid anchors (orange) exhibit no binding or toxicity towards RBCs, yet display strong binding and immunosuppression properties to both WBCs granulocytes and PBMCs in HBSS.

The impact of cholesterol-mediated selectivity may lie in the field of vaccine development and drug targeting. Cholesterol tags or other membranes-selective moieties may be used as a route to target functional DNA or RNA cargo towards immune cells thereby complementing aptamerbased recognition..$^{72}$ Vaccine development could benefit from this selective interaction as nucleic acid vaccines have to be taken up by immune cells to translate the genetic information into a protein that elicits the immune response. Cholesterol-mediated binding may also be a general basis to assist targeting other biomedically relevant substances to immune cells, especially for immunomodulation. While our data shows that cholesterol is a main source for selectivity, binding can also be modulated by membrane proteins. Protein interaction may, for example, explain the small 3-fold difference in binding between the two WBC subclasses of granulocytes and PBMCs which have similar cholesterol levels. ${ }^{50}$ Future work may explore the specific reason for the small differences, as well as binding to PBMC fractions of monocytes and lymphocyte subsets, or 
towards platelets. Similarly, more research should help tackle aggregation of DNA barrels in serum, which is either due to electrostatic or hydrophobic interactions. Tested recourses include masking negative charges using charge neutralized DNA or PNA, ${ }^{73}$ coating by proteins or PEG moieties ${ }^{39,74}$ or placing cholesterol lipid anchors in less accessible, recessed positions along the DNA nanostructure. ${ }^{75}$ To exploit the findings for vaccine development, mRNA nanostructures would be created in future research from synthetic oligonucleotide sequences which encode an antigen of the infectious agent including a virus. The nanostructures would be tagged with the membrane-targeting moiety. Following injection into the body, such as a mouse model, the mRNA structure would enter host cells including dendritic cells to produce antigens. These antigens would be presented to lymphocytes to stimulate cell mediated immunity and antibody production.

As second insight, avid cholesterol-mediated binding to white blood cells did not lead to membrane rupturing. The non-toxic behavior is beneficial for any future biomedical applications, yet surprising as the cholesterol nanobarrels are known to porate synthetic membranes. ${ }^{54}$ The barrels are non-toxic to cells as one cholesterol tag is sufficient for membrane tethering, while complete membrane insertion with three cholesterols likely blocked by crowding-out from proteins on the membrane surface. These non-toxic properties are specific for cholesterol as toxicity has been reported for a DNA barrel with another lipid anchor based using charge-neutralized DNA backbones. ${ }^{76}$

Thirdly, the membrane-bound DNA nanostructures were discovered to repress immune cell responses to endotoxin (Figure 6). DNA usually activates the immune system ${ }^{15}$ and CG repeat sequences have been shown to enhance this response. ${ }^{77}$ Consistent with the literature, our cholesterol-tagged DNA nanobarrels elicited the release of proinflammatory cytokines in a dosedependent manner in serum. However, DNA barrels reduced the cytokine release from leukocytes that were incubated with pro-inflammatory stimulus lipopolysaccharide (LPS). Without barrel preincubation, LPS led to the expected inflammatory cytokine release. A possible explanation could

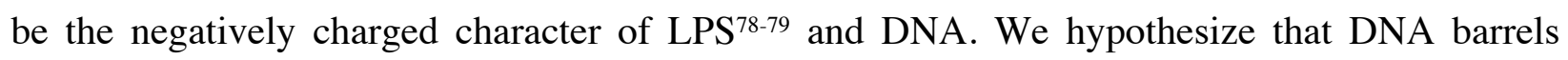
electrostatically block LPS engagement to the cognate surface toll-like receptors, thereby resulting in an attenuated downstream cascade activation and reduced immune response. In this model, the more DNA nanobarrel binding, the greater the ionic repulsion between negative charges in LPS 
and DNA. Future research should explore other functional responses of immune cells including immune cell migration, phagocytosis, and cell proliferation.

In conclusion, our study has yielded scientific insight into the behavior of compact DNA nanostructures in a multicellular environment with biomedical impact for potential therapeutic applications. Promising routes include the development of vaccines to deliver compact and nuclease-resistant DNA to target immune cells. In addition, in immunomodulatory therapy DNA structure binding could help tackle septic shock by decreasing the exaggerated host response to infection as supported by the abrogated LPS response of immune cells. Other applications of attenuated immune cell response include transplant immunosuppression and autoimmune disease. We hope our findings can catalyze research into these biomedically important areas.

\section{METHODS/EXPERIMENTAL}

Reagents. All other reagents were purchased from Sigma Aldrich (UK) unless stated otherwise.

Folding of DNA nanostructures. The structure of the DNA nanobarrel was published previously (information on the sequences, including 2D maps and dimensions is provided in the Supporting Information). ${ }^{53}$ The DNA nanobarrels were assembled by mixing an equimolar mixture of the component DNA strands $(1 \mu \mathrm{M})$ (Integrated DNA Technologies, US) containing the stated buffer or media. The constructs were folded by heating the solution from $95{ }^{\circ} \mathrm{C}$ for $2 \mathrm{~min}$, and cooling to $20{ }^{\circ} \mathrm{C}$ at a rate of $5{ }^{\circ} \mathrm{C}$ per min. The assembled constructs were stored at room temperature and vortexed for $2 \mathrm{~s}$ before use and used within $24 \mathrm{~h}$.

Polyacrylamide gel electrophoretic analysis of folded DNA nanostructures. The DNA nanobarrels (2 $\mu \mathrm{L}, 1 \mu \mathrm{M}$ in PBS) were added to buffer (13 $\mu \mathrm{L}$, PBS unless otherwise specified) and gel loading dye $(5 \mu \mathrm{L}$, purple loading dye). Each sample $(8 \mu \mathrm{L})$ was loaded into wells of a thermally equilibrated PAGE gel (10\% in 1x TBE buffer for native or 1x TGS buffer for SDS PAGE, at $115 \mathrm{~V}$ for $60 \mathrm{~min}$ at $4{ }^{\circ} \mathrm{C}$ ). Once complete, the bands were visualized by first washing in de-ionized water, and then stained with ethidium bromide solution.

Agarose gel electrophoresis. The DNA nanobarrels $(2 \mu \mathrm{L}, 1 \mu \mathrm{M}$ in PBS $)$ were added to buffer (13 $\mu \mathrm{L}, \mathrm{PBS})$ and gel loading dye $(5 \mu \mathrm{L}, \mathrm{SDS}-$ free $)$. The solution $(15 \mu \mathrm{L})$ was loaded into the wells 
of a thermally equilibrated agarose gel ( $2 \%$ in $1 x$ TAE buffer, containing ethidium bromide), and run at $60 \mathrm{~V}$ for $60 \mathrm{~min}$ at $4{ }^{\circ} \mathrm{C}$.

Whole blood and serum preparation. Whole blood $(5 \mathrm{~mL})$ was collected in heparinized syringes from healthy donors. Cells were separated from plasma by centrifugation for $15 \mathrm{~min}$ at 2,000 x $\mathrm{g}$ using a refrigerated centrifuge. The resulting supernatant containing plasma was extracted and used immediately or stored at $-20{ }^{\circ} \mathrm{C}$ prior to further use. Repeated freeze thaw cycles were avoided. To heat-inactivate human serum, the media was incubated at $60{ }^{\circ} \mathrm{C}$ for $20 \mathrm{~min}$. All exvivo cell experiments were carried out at $37^{\circ} \mathrm{C}$ in a cell culture chamber.

Nanostructure stability assay with melting profile analysis. The melting transitions of the DNA nanostructures were identified following a published procedure ${ }^{59}$ using a MyIQ real-time PCR (Bio-Rad, Watford, UK). The nanostructures were assembled containing FAM and TAMRA FRET pairs (folded at $1 \mu \mathrm{M}$ in PBS). The DNA constructs were diluted into the stated buffer systems to give a final DNA concentration of $0.1 \mu \mathrm{M}$ (total volume of $25 \mu \mathrm{L}$ ) in a 96-well thin wall fluorescence plate (Bio-Rad, Watford, UK). Optical quality sealing tape (Bio-Rad, Watford, UK) was placed on top to prevent evaporation. The samples were heated from 30 to $85^{\circ} \mathrm{C}$ at a rate of $0.5^{\circ} \mathrm{C}$ per min. The melting temperature was determined from taking the $1^{\text {st }}$ derivative of the donor fluorescence profile. Errors were identified from three independent experiments. Additional UV absorbance melting profiles for NB-3C and DNA tetrahedron $(0.5 \mu \mathrm{M}$, in $1 \mathrm{x}$ DNAse I buffer) were conducted using a Varian Cary 300 Bio UV/Vis spectrophotometer by heating from $20{ }^{\circ} \mathrm{C}$ to $80{ }^{\circ} \mathrm{C}$ at a rate of $1{ }^{\circ} \mathrm{C}$ per min, collecting data at $1^{\circ} \mathrm{C}$ intervals scanning at $260 \mathrm{~nm}$.

Isolation of white blood cells for confocal laser scanning microscopy and flow cytometry. Whole blood ( 5 to $10 \mathrm{~mL}$ ) was collected in heparinized syringes from healthy donors. RBCs were lysed using 1x red cell lysis buffer (BD; Beckton Dickinson biosciences, UK) containing 16\% formaldehyde. Cells were washed and re-suspended in either human serum $(5 \mathrm{~mL})$ or HBSS (5 $\mathrm{mL}$ ), for serum and serum-free conditions, respectively. The nuclear stain 4',6-diamidino-2phenylindole (DAPI) (Thermo Fisher Scientific, UK) at $5 \mu \mathrm{g}$ per $\mathrm{mL}$ was added to visualize WBCs for confocal microscopy and flow cytometry. 
Confocal laser scanning microscopy. CLSM images were collected using a 60x oil objective mounted on a FV-1000 Olympus microscope, solutions were deposited on a fluorodish (World Precision Instruments, Sarasota, FL, USA) and left to settle for 5 min before imaging. For serum stability assays, the DNA solution ( $20 \mu \mathrm{L}, 1 \mu \mathrm{M}$ in PBS) was added to either HBSS, human serum or heat-inactivated human serum $(20 \mu \mathrm{L})$ and mixed for 5 mins. Where stated WBCs $(2 \mu \mathrm{L})$ were additionally added and deposited on the confocal dish. For kinetic WBC binding assays, WBCs (in HBSS or human serum, $10 \mu \mathrm{L}$ ) were added to a confocal dish and left to settle for 5 mins, followed by addition of the DNA solution (10 $\mu \mathrm{L}, 1 \mu \mathrm{M}$ in PBS). All imaging conditions were kept identical when comparing different DNA barrel constructs and controls. Images were analyzed using ImageJ software. The binding selectivity was calculated using ImageJ software. The data was derived from the CLSM images by comparing the fluorescence intensity of the WBC and the RBC membranes. The results show $>400$-fold difference in membrane binding as the RBC gave no detectable fluorescence.

Fluorescence activated cell sorting. Cells were analyzed on the LSR Fortessa (BD) flow cytometer (BD Biosciences). The two main cell populations, granulocytes and peripheral blood mononuclear cells were identified by gating on characteristic forward and side scatter profiles. Identical gates were applied to all samples. Minimum of 5000 events/measurement within the granulocyte population were read. For binding assays, the DNA solutions ( $200 \mu \mathrm{L}, 500 \mathrm{nM}$ in PBS) were added to WBCs (in HBSS or HS, $200 \mu \mathrm{L}$ ) and incubated for $90 \mathrm{~min}$. All data were collected from three individual replicates per experiment and geometric mean assessed using FlowJo version 10.0 (Tree Star Inc, USA). Statistical data analyzed using a non-parametric Mann Whitney t-test using GraphPad Prism v5 (San Diego, USA).

White blood cell viability. The DNA solutions ( $1 \mathrm{~mL}, 500 \mathrm{nM}$ in PBS) were added to WBCs (in HBSS, $1 \mathrm{~mL}$ ) and incubated for $6 \mathrm{~h}$. Viability of cells was determined by the addition of far red live/dead stain (Thermo Fisher Scientific, UK) 20 min prior to fixation with formaldehyde at 37 ${ }^{\circ} \mathrm{C}$. As a positive control for dead cells, cells were incubated at $60{ }^{\circ} \mathrm{C}$ for $10 \mathrm{~min}$.

Haemolysis. The DNA nanobarrels ( $20 \mu \mathrm{L}, 1 \mu \mathrm{M}$ in PBS) were added to RBCs (in HS or HBSS $20 \mu \mathrm{L}$ ) and the solution mixed for $4 \mathrm{~h}$. The extent of lysis was determined by diluting the solution $(15 \mu \mathrm{L})$ in PBS $(600 \mu \mathrm{L})$ and monitoring the UV-vis absorbance. Experiments were performed in triplicate. 
White blood cell activation. Immune cell reactive oxygen species (ROS) was determined by preincubating blood (in HBSS, $2 \mathrm{~mL}$ ) with dihydroethidium $(5 \mu \mathrm{M})$ or H2-DCFDA $(5 \mu \mathrm{M})$ (Thermo Fisher Scientific, UK) for $30 \mathrm{~min}$ at $37^{\circ} \mathrm{C}$ prior to the addition of the DNA constructs (2 $\mathrm{mL}, 500 \mathrm{nM}$ in PBS) or other stimuli. Phorbol 12-myristate 13-acetate (PMA) and inomicin (eBioscience cell stimulation cocktail) was used to activate neutrophils either as a positive control for reactive oxygen species (ROS), or to assess PMN ROS capacity following incubation with DNA constructs. Lipopolysaccharide was obtained from Sigma and used at a concentration of 100 ng per mL. Water soluble cholesterol-PEG 600 was obtained from Sigma (C1145) and used at a concentration of $750 \mathrm{nM}$.

ELISA. Release of TNF-alpha and IL-6 from immune cells in either whole blood or supernatants was measured using ELISA. The DNA constructs ( $5 \mathrm{~mL}, 500 \mathrm{nM}$ in PBS) were incubated with whole blood $(5 \mathrm{~mL})$ up to $8 \mathrm{~h}$. Whole blood samples were centrifuged, and plasma used for analysis of cytokine levels. DuoSet ELISA kits (R\&D Systems, Minneapolis, MN, and BD Biosciences, Oxford, Oxon, UK) were used to assess cytokine levels according to the manufacturers' instructions. Absorbance was read at $450 \mathrm{~nm}$ using a spectrophotometric ELISA plate reader (Anthos HTII; Anthos Labtec, Salzburg, Austria).

\section{ASSOCIATED CONTENT}

\section{Supporting Information}

The Supporting Information is available free of charge on the ACS Publications website at DOI. Design of DNA nanobarrels, DNA sequences, 2D maps of DNA nanobarrels, structural characterization of DNA nanostructures, melting profile analysis of DNA nanobarrels and tetrahedrons, agarose gel analysis of DNA nanobarrels in different biological media and of tetrahedrons, CLSM analysis of NB-3C with human serum and heat-inactivated human serum, CLSM analysis on the co-localisation of NB-3C with immune cells, flow cytometry analysis of DNA nanobarrel binding to WBCs, LPS-induced TNF-alpha release in whole blood and HBSS, effect of cholesterol-PEG on LPS-induced TNF-alpha response

\section{AUTHOR INFORMATION}




\section{Corresponding Author}

* Correspondence and requests for materials should be addressed to J.R.B.

(jonathan.burns@ucl.ac.uk), M.S.(m.singer@ucl.ac.uk), and S.H. (s.howorka@ucl.ac.uk).

\section{Author Contributions}

N.A. prepared plasma and whole blood, isolated immune cells, performed flow cytometry analysis, prepared cells for confocal microscopy and conducted confocal microscopy. N.A. also carried out cell viability and immune assays, analyzed data, and wrote the manuscript. C.L. assembled DNA nanostructures, analyzed them via gel electrophoresis, FRET melting profiles, and conducted data analysis. C.G. isolated immune cells, conducted flow cytometry, and performed data analysis. J.R.B. carried out confocal microscopy and assays on binding kinetics and haemolysis, analyzed data, and wrote the manuscript. M.S. edited the manuscript. S.H. wrote the manuscript.

\section{ACKNOWLEDGMENT}

N.A. is supported by the NIRH as an academic clinical lecturer and received a Start-up grant from the Academy of Medical Sciences. The Howorka Group receives funding from the BBSRC (BB/N017331/1), and the Leverhulme Trust (RPG-2017-015). Conor Lanphere is supported by the BBSRC (BB/MO09513/1) and by the National Physical Laboratory.

\section{REFERENCES}

1. Rothemund, P. W. Folding DNA to Create Nanoscale Shapes and Patterns. Nature 2006, 440, 297-302.

2. Seeman, N. C.; Sleiman, H. F. DNA Nanotechnology. Nat. Rev. Mater. 2017, 3, 17068.

3. Hong, F.; Zhang, F.; Liu, Y.; Yan, H. DNA Origami: Scaffolds for Creating Higher Order Structures. Chem. Rev. 2017, 117, 12584-12640.

4. Praetorius, F.; Kick, B.; Behler, K. L.; Honemann, M. N.; Weuster-Botz, D.; Dietz, H. Biotechnological Mass Production of DNA Origami. Nature 2017, 552, 84-87.

5. Sacca, B.; Niemeyer, C. M. DNA Origami: The Art of Folding DNA. Angew. Chem. Int. Ed. 2012, 51, 58-66. 
6. Douglas, S. M.; Dietz, H.; Liedl, T.; Hogberg, B.; Graf, F.; Shih, W. M. Self-Assembly of DNA into Nanoscale Three-Dimensional Shapes. Nature 2009, 459, 414-418.

7. Fu, J.; Yang, Y. R.; Johnson-Buck, A.; Liu, M.; Liu, Y.; Walter, N. G.; Woodbury, N. W.; Yan, H. Multi-Enzyme Complexes on DNA Scaffolds Capable of Substrate Channelling with an Artificial Swinging Arm. Nat. Nanotechnol. 2014, 9, 531-536.

8. Zheng, J. P.; Birktoft, J. J.; Chen, Y.; Wang, T.; Sha, R. J.; Constantinou, P. E.; Ginell, S. L.; Mao, C. D.; Seeman, N. C. From Molecular to Macroscopic via the Rational Design of a SelfAssembled 3D DNA Crystal. Nature 2009, 461, 74-77.

9. Delebecque, C. J.; Lindner, A. B.; Silver, P. A.; Aldaye, F. A. Organization of Intracellular Reactions with Rationally Designed RNA Assemblies. Science 2011, 333, 470-474.

10. Bhatia, D.; Surana, S.; Chakraborty, S.; Koushika, S. P.; Krishnan, Y. A Synthetic Icosahedral DNA-Based Host-Cargo Complex for Functional in Vivo Imaging. Nat. Commun. 2011, 2, 339.

11. Modi, S.; M, G. S.; Goswami, D.; Gupta, G. D.; Mayor, S.; Krishnan, Y. A DNA Nanomachine That Maps Spatial and Temporal pH Changes inside Living Cells. Nat. Nanotechnol. 2009, 4, 325-330.

12. Modi, S.; Nizak, C.; Surana, S.; Halder, S.; Krishnan, Y. Two DNA Nanomachines Map pH Changes along Intersecting Endocytic Pathways inside the Same Cell. Nat. Nanotechnol. 2013, $8,459-467$.

13. Walsh, A. S.; Yin, H.; Erben, C. M.; Wood, M. J.; Turberfield, A. J. DNA Cage Delivery to Mammalian Cells. ACS Nano 2011, 5, 5427-5432.

14. Chen, Y. J.; Groves, B.; Muscat, R. A.; Seelig, G. DNA Nanotechnology from the Test Tube to the Cell. Nat. Nanotechnol. 2015, 10, 748-760.

15. Surana, S.; Shenoy, A. R.; Krishnan, Y. Designing DNA Nanodevices for Compatibility with the Immune System of Higher Organisms. Nat. Nanotechnol. 2015, 10, 741-747.

16. Lanphere, C.; Arnott, P. M.; Jones, S. F.; Korlova, K.; Howorka, S. A Biomimetic DNABased Membrane Gate for Protein-Controlled Transport of Cytotoxic Drugs Angew. Chem. Int. Ed. 2020, doi:10.1002/ange.202011583

17. Li, S.; Jiang, Q.; Liu, S.; Zhang, Y.; Tian, Y.; Song, C.; Wang, J.; Zou, Y.; Anderson, G. J.; Han, J. Y.; Chang, Y.; Liu, Y.; Zhang, C.; Chen, L.; Zhou, G.; Nie, G.; Yan, H.; Ding, B.; Zhao, 
Y. A DNA Nanorobot Functions as a Cancer Therapeutic in Response to a Molecular Trigger in vivo. Nat. Biotechnol. 2018, 36, 258-264.

18. Jiang, D.; Ge, Z.; Im, H. J.; England, C. G.; Ni, D.; Hou, J.; Zhang, L.; Kutyreff, C. J.; Yan, Y.; Liu, Y.; Cho, S. Y.; Engle, J. W.; Shi, J.; Huang, P.; Fan, C.; Yan, H.; Cai, W. DNA Origami Nanostructures Can Exhibit Preferential Renal Uptake and Alleviate Acute Kidney Injury. Nat. Biomed. Eng. 2018, 2, 865-877.

19. Jiang, D.; Sun, Y.; Li, J.; Li, Q.; Lv, M.; Zhu, B.; Tian, T.; Cheng, D.; Xia, J.; Zhang, L.; Wang, L.; Huang, Q.; Shi, J.; Fan, C. Multiple-Armed Tetrahedral DNA Nanostructures for Tumor-Targeting, Dual-Modality in Vivo Imaging. ACS Appl. Mater. Interfaces 2016, 8, 43784384 .

20. Gary, E. N.; Weiner, D. B. DNA Vaccines: Prime Time Is Now. Curr. Opin. Immunol. 2020, 65, 21-27.

21. Sahin, U.; Oehm, P.; Derhovanessian, E.; Jabulowsky, R. A.; Vormehr, M.; Gold, M.; Maurus, D.; Schwarck-Kokarakis, D.; Kuhn, A. N.; Omokoko, T.; Kranz, L. M.; Diken, M.; Kreiter, S.; Haas, H.; Attig, S.; Rae, R.; Cuk, K.; Kemmer-Bruck, A.; Breitkreuz, A.; Tolliver, C., et al. An RNA Vaccine Drives Immunity in Checkpoint-Inhibitor-Treated Melanoma. Nature 2020, 585, 107-112.

22. Pardi, N.; Hogan, M. J.; Porter, F. W.; Weissman, D. mRNA Vaccines - A New Era in Vaccinology. Nat. Rev. Drug Discov. 2018, 17, 261-279.

23. Nguyen, T. L.; Yin, Y.; Choi, Y.; Jeong, J. H.; Kim, J. Enhanced Cancer DNA Vaccine via Direct Transfection to Host Dendritic Cells Recruited in Injectable Scaffolds. ACS Nano 2020, 14 , 11623-11636.

24. Jeyanathan, M.; Afkhami, S.; Smaill, F.; Miller, M. S.; Lichty, B. D.; Xing, Z. Immunological Considerations for Covid-19 Vaccine Strategies. Nat. Rev. Immunol. 2020, doi: 10.1038/s41577-41020-00434-41576.

25. Lurie, N.; Saville, M.; Hatchett, R.; Halton, J. Developing Covid-19 Vaccines at Pandemic Speed. N. Engl. J. Med. 2020, 382, 1969-1973.

26. Yu, J.; Tostanoski, L. H.; Peter, L.; Mercado, N. B.; McMahan, K.; Mahrokhian, S. H.; Nkolola, J. P.; Liu, J.; Li, Z.; Chandrashekar, A.; Martinez, D. R.; Loos, C.; Atyeo, C.; Fischinger, S.; Burke, J. S.; Slein, M. D.; Chen, Y.; Zuiani, A.; Lelis, F. J. N.; Travers, M., et al. DNA Vaccine Protection against SARS-CoV-2 in Rhesus Macaques. Science 2020, 369, 806-811. 
27. Jackson, L. A.; Anderson, E. J.; Rouphael, N. G.; Roberts, P. C.; Makhene, M.; Coler, R. N.; McCullough, M. P.; Chappell, J. D.; Denison, M. R.; Stevens, L. J.; Pruijssers, A. J.; McDermott, A.; Flach, B.; Doria-Rose, N. A.; Corbett, K. S.; Morabito, K. M.; O'Dell, S.; Schmidt, S. D.; Swanson, P. A., 2nd; Padilla, M., et al. An mRNA Vaccine against SARS-CoV-2 Preliminary Report. N. Engl. J. Med. 2020, 383, 1920-1931.

28. Corbett, K. S.; Flynn, B.; Foulds, K. E.; Francica, J. R.; Boyoglu-Barnum, S.; Werner, A. P.; Flach, B.; O'Connell, S.; Bock, K. W.; Minai, M.; Nagata, B. M.; Andersen, H.; Martinez, D. R.; Noe, A. T.; Douek, N.; Donaldson, M. M.; Nji, N. N.; Alvarado, G. S.; Edwards, D. K.; Flebbe, D. R., et al. Evaluation of the mRNA-1273 Vaccine against SARS-CoV-2 in Nonhuman Primates. N. Engl.J. Med.2020, 383, 1544-1555.

29. McKay, P. F.; Hu, K.; Blakney, A. K.; Samnuan, K.; Brown, J. C.; Penn, R.; Zhou, J.; Bouton, C. R.; Rogers, P.; Polra, K.; Lin, P. J. C.; Barbosa, C.; Tam, Y. K.; Barclay, W. S.; Shattock, R. J. Self-Amplifying RNA SARS-CoV-2 Lipid Nanoparticle Vaccine Candidate Induces High Neutralizing Antibody Titers in Mice. Nat. Commun. 2020, 11, 3523.

30. Hobernik, D.; Bros, M. DNA Vaccines-How Far from Clinical Use? Int. J. Mol. Sci. 2018, 19,3605 .

31. Phua, K. K.; Leong, K. W.; Nair, S. K. Transfection Efficiency and Transgene Expression Kinetics of mRNA Delivered in Naked and Nanoparticle Format. J. Control. Release 2013, 166, 227-233.

32. Weniger, B. G.; Anglin, I. E.; Tong, T.; Pensiero, M.; Pullen, J. K.; Nucleic Acid Delivery Devices for, H. I. V. V. W. G. Workshop Report: Nucleic Acid Delivery Devices for HIV Vaccines: Workshop Proceedings, National Institute of Allergy and Infectious Diseases, Bethesda, Maryland, USA, May 21, 2015. Vaccine 2018, 36, 427-437.

33. Salem, A. K.; Searson, P. C.; Leong, K. W. Multifunctional Nanorods for Gene Delivery. Nat. Mater 2003, 2, 668-671.

34. Zhang, M.; Hong, Y.; Chen, W.; Wang, C. Polymers for DNA Vaccine Delivery. ACS Biomater. Sci. Eng. 2017, 3, 108-125.

35. Yan, J.; Chen, R.; Zhang, H.; Bryers, J. D. Injectable Biodegradable Chitosan-Alginate 3D Porous Gel Scaffold for mRNA Vaccine Delivery. Macromol Biosci 2019, 19, e1800242.

36. Lostalé-Seijo, I.; Montenegro, J. Synthetic Materials at the Forefront of Gene Delivery. Nat. Rev. Chem. 2018, 2, 258-277. 
37. Riley, R. S.; June, C. H.; Langer, R.; Mitchell, M. J. Delivery Technologies for Cancer Immunotherapy. Nat. Rev. Drug. Discov. 2019, 18, 175-196.

38. Perrault, S. D.; Shih, W. M. Virus-Inspired Membrane Encapsulation of DNA Nanostructures to Achieve in Vivo Stability. ACS Nano 2014, 8, 5132-5140.

39. Ponnuswamy, N.; Bastings, M. M. C.; Nathwani, B.; Ryu, J. H.; Chou, L. Y. T.; Vinther, M.; Li, W. A.; Anastassacos, F. M.; Mooney, D. J.; Shih, W. M. Oligolysine-Based Coating Protects DNA Nanostructures from Low-Salt Denaturation and Nuclease Degradation. Nat. Commun. 2017, 8, 15654.

40. Sellner, S.; Kocabey, S.; Nekolla, K.; Krombach, F.; Liedl, T.; Rehberg, M. DNA Nanotubes as Intracellular Delivery Vehicles in Vivo. Biomaterials 2015, 53, 453-463.

41. Hu, Q.; Wang, S.; Wang, L.; Gu, H.; Fan, C. DNA Nanostructure-Based Systems for Intelligent Delivery of Therapeutic Oligonucleotides. Adv. Healthc. Mater. 2018, 7, e1701153.

42. Auvinen, H.; Zhang, H.; Nonappa; Kopilow, A.; Niemela, E. H.; Nummelin, S.; Correia, A.; Santos, H. A.; Linko, V.; Kostiainen, M. A. Protein Coating of DNA Nanostructures for Enhanced Stability and Immunocompatibility. Adv. Healthc. Mater. 2017, 6, 1700692.

43. Hahn, J.; Wickham, S. F.; Shih, W. M.; Perrault, S. D. Addressing the Instability of DNA Nanostructures in Tissue Culture. ACS Nano 2014, 8, 8765-8775.

44. Ko, S.; Liu, H.; Chen, Y.; Mao, C. DNA Nanotubes as Combinatorial Vehicles for Cellular Delivery. Biomacromolecules 2008, 9, 3039-3043.

45. Li, J.; Pei, H.; Zhu, B.; Liang, L.; Wei, M.; He, Y.; Chen, N.; Li, D.; Huang, Q.; Fan, C. Self-Assembled Multivalent DNA Nanostructures for Noninvasive Intracellular Delivery of Immunostimulatory CpG Oligonucleotides. ACS Nano 2011, 5, 8783-8789.

46. Wang, P.; Rahman, M. A.; Zhao, Z.; Weiss, K.; Zhang, C.; Chen, Z.; Hurwitz, S. J.; Chen, Z. G.; Shin, D. M.; Ke, Y. Visualization of the Cellular Uptake and Trafficking of DNA Origami Nanostructures in Cancer Cells. J. Am. Chem. Soc. 2018, 140, 2478-2484.

47. Zagorovsky, K.; Chou, L. Y.; Chan, W. C. Controlling DNA-Nanoparticle Serum Interactions. Proc. Natl. Acad. Sci. USA 2016, 113, 13600-13605.

48. Bastings, M. M. C.; Anastassacos, F. M.; Ponnuswamy, N.; Leifer, F. G.; Cuneo, G.; Lin, C.; Ingber, D. E.; Ryu, J. H.; Shih, W. M. Modulation of the Cellular Uptake of DNA Origami through Control over Mass and Shape. Nano Lett. 2018, 18, 3557-3564. 
49. Hong, E.; Halman, J. R.; Shah, A. B.; Khisamutdinov, E. F.; Dobrovolskaia, M. A.; Afonin, K. A. Structure and Composition Define Immunorecognition of Nucleic Acid Nanoparticles. Nano Lett. 2018, 18, 4309-4321.

50. Leidl, K.; Liebisch, G.; Richter, D.; Schmitz, G. Mass Spectrometric Analysis of Lipid Species of Human Circulating Blood Cells. Biochim. Biophys. Acta 2008, 1781, 655-664.

51. Cooper, R. A. Influence of Increased Membrane Cholesterol on Membrane Fluidity and Cell Function in Human Red Blood Cells. J. Supramol. Struct. 1978, 8, 413-430.

52. Owen, J. S.; Bruckdorfer, K. R.; Day, R. C.; McIntyre, N. Decreased Erythrocyte Membrane Fluidity and Altered Lipid Composition in Human Liver Disease. J. Lipid Res. 1982, $23,124-132$.

53. Burns, J. R.; Seifert, A.; Fertig, N.; Howorka, S. A Biomimetic DNA-Based Channel for the Ligand-Controlled Transport of Charged Molecular Cargo across a Biological Membrane. Nat. Nanotechnol. 2016, 11, 152-156.

54. Burns, J. R.; Howorka, S. Defined Bilayer Interactions of DNA Nanopores Revealed with a Nuclease-Based Nanoprobe Strategy. ACS Nano 2018, 12, 3263-3271.

55. Birkholz, O.; Burns, J. R.; Richter, C. P.; Psathaki, O. E.; Howorka, S.; Piehler, J. MultiFunctional DNA Nanostructures That Puncture and Remodel Lipid Membranes into Hybrid Materials. Nat. Commun. 2018, 9, 1521.

56. Howorka, S. Nanotechnology. Changing of the Guard. Science 2016, 352, 890-891.

57. Pugh, G. C.; Burns, J. R.; Howorka, S. Comparing Proteins and Nucleic Acids for NextGeneration Biomolecular Engineering. Nat. Rev. Chem. 2018, 2, 113-130.

58. Wei, X.; Nangreave, J.; Jiang, S.; Yan, H.; Liu, Y. Mapping the Thermal Behavior of DNA Origami Nanostructures. J. Am. Chem. Soc. 2013, 135, 6165-6176.

59. Burns, J. R.; Howorka, S. Structural and Functional Stability of DNA Nanopores in Biological Media. Nanomaterials 2019, 9, 490.

60. Lacroix, A.; Vengut-Climent, E.; de Rochambeau, D.; Sleiman, H. F. Uptake and Fate of Fluorescently Labeled DNA Nanostructures in Cellular Environments: A Cautionary Tale. ACS Cent. Sci. 2019, 5, 882-891.

61. Brinkmann, V.; Reichard, U.; Goosmann, C.; Fauler, B.; Uhlemann, Y.; Weiss, D. S.; Weinrauch, Y.; Zychlinsky, A. Neutrophil Extracellular Traps Kill Bacteria. Science 2004, 303, $1532-1535$. 
62. Hidalgo, A.; Chilvers, E. R.; Summers, C.; Koenderman, L. The Neutrophil Life Cycle. Trends Immunol 2019, 40, 584-597.

63. Paludan, S. R. Activation and Regulation of DNA-Driven Immune Responses. Microbiol. Mol. Biol. Rev. 2015, 79, 225-241.

64. Atianand, M. K.; Fitzgerald, K. A. Molecular Basis of DNA Recognition in the Immune System. J. Immunol. 2013, 190, 1911-1918.

65. Dikalov, S. I.; Harrison, D. G. Methods for Detection of Mitochondrial and Cellular Reactive Oxygen Species. Antioxid. Redox Signal 2014, 20, 372-382.

66. Qu, Y.; Yang, J.; Zhan, P.; Liu, S.; Zhang, K.; Jiang, Q.; Li, C.; Ding, B. Self-Assembled DNA Dendrimer Nanoparticle for Efficient Delivery of Immunostimulatory CpG Motifs. ACS Appl. Mater. Interfaces 2017, 9, 20324-20329.

67. Schuller, V. J.; Heidegger, S.; Sandholzer, N.; Nickels, P. C.; Suhartha, N. A.; Endres, S.; Bourquin, C.; Liedl, T. Cellular Immunostimulation by CpG-Sequence-Coated DNA Origami Structures. ACS Nano 2011, 5, 9696-9702.

68. Yang, Y.; Bazhin, A. V.; Werner, J.; Karakhanova, S. Reactive Oxygen Species in the Immune System. Int. Rev. Immunol. 2013, 32, 249-270.

69. Huang, R.; Zhao, L.; Chen, H.; Yin, R. H.; Li, C. Y.; Zhan, Y. Q.; Zhang, J. H.; Ge, C. H.; Yu, M.; Yang, X. M. Megakaryocytic Differentiation of K562 Cells Induced by PMA Reduced the Activity of Respiratory Chain Complex IV. PLoS ONE 2014, 9, e96246.

70. Munford, R. S.; Andersen, J. M.; Dietschy, J. M. Sites of Tissue Binding and Uptake in Vivo of Bacterial Lipopolysaccharide-High Density Lipoprotein Complexes: Studies in the Rat and Squirrel Monkey. J. Clin. Invest. 1981, 68, 1503-1513.

71. Falck, E.; Patra, M.; Karttunen, M.; Hyvonen, M. T.; Vattulainen, I. Lessons of Slicing Membranes: Interplay of Packing, Free Area, and Lateral Diffusion in Phospholipid/Cholesterol Bilayers. Biophys. J. 2004, 87, 1076-1091.

72. Sakai, Y.; Islam, M. S.; Adamiak, M.; Shiu, S. C.; Tanner, J. A.; Heddle, J. G. DNA Aptamers for the Functionalisation of DNA Origami Nanostructures. Genes 2018, 9, 571.

73. Flory, J. D.; Shinde, S.; Lin, S.; Liu, Y.; Yan, H.; Ghirlanda, G.; Fromme, P. PNA-Peptide Assembly in a 3D DNA Nanocage at Room Temperature. J. Am. Chem. Soc. 2013, 135, 69856993. 
74. Mikkilä, J.; Eskelinen, A. P.; Niemelä, E. H.; Linko, V.; Frilander, M. J.; Törmä, P.; Kostiainen, M. A. Virus-Encapsulated DNA Origami Nanostructures for Cellular Delivery. Nano Lett. 2014, 14, 2196-2200.

75. Ohmann, A.; Gopfrich, K.; Joshi, H.; Thompson, R. F.; Sobota, D.; Ranson, N. A.; Aksimentiev, A.; Keyser, U. F. Controlling Aggregation of Cholesterol-Modified DNA Nanostructures. Nucleic Acids Res. 2019, 47, 11441-11451.

76. Burns, J. R.; Al-Juffali, N.; Janes, S. M.; Howorka, S. Membrane-Spanning DNA Nanopores with Cytotoxic Effect. Angew. Chem. Int. Ed. 2014, 53, 12466-12470.

77. Marsman, G.; Zeerleder, S.; Luken, B. M. Extracellular Histones, Cell-Free DNA, or Nucleosomes: Differences in Immunostimulation. Cell Death Dis. 2016, 7, e2518.

78. Adams, P. G.; Lamoureux, L.; Swingle, K. L.; Mukundan, H.; Montano, G. A. Lipopolysaccharide-Induced Dynamic Lipid Membrane Reorganization: Tubules, Perforations, and Stacks. Biophys. J. 2014, 106, 2395-2407.

79. Raetz, C. R.; Whitfield, C. Lipopolysaccharide Endotoxins. Annu.Rev. Biochem. 2002, 71, 635-700. 